\title{
A BRIEF HISTORY OF DOPE DETECTION IN RACEHORSES
}

\author{
*E. G. C. CLARKE, M.A., D.Sc., F.R.I.C. \& TM. S. MOSS, M.Sc. \\ *Emeritus Professor of Chemical Toxicology, Royal Veterinary College, University of London \\ tDirector, Racecourse Security Services Laboratories, Newmarket, Suffolk
}

In an age when doping was almost a way of life it was only a short step from the poisoning of man to the poisoning of animals. In classical antiquity there are examples of both doping to win and doping to lose. Diomedes, the son of Aries and Cyrene, fed his horses on human flesh to make them savage and unbeatable, while Medea used an opiate to stupefy the dragon that guarded the Golden Fleece. Although the reference in the book of Maccabees to the use of the juice of grapes and mulberries to rouse the war elephants to battle is probably an imprecise translation, according to Marco Polo there seems little doubt that these animals were given wine for this purpose. It is said that in Roman times hydromel, a mixture of water and honey, was used to improve the performance of chariot horses.

No reference to the doping of horses in this country is available until the seventeenth century when a regulation dated 1666 banned the use of exciting substances in races at Worksop. The first well documented cases of horse "doping" in England occurred with the trial of Daniel Dawson at Cambridge assizes in 1812 for the poisoning of horses with arsenic, but doping as opposed to the poisoning of horses did not become widespread until the first decade of this century. It is said to have been introduced to Europe from America. The practice spread like wildfire and became a serious embarrassment to the racing authorities.

By 1910 things had become so bad that the Austrian racing authorities called in the services of a Russian chemist, Bukowski, who demonstrated that it was possible to detect the presence of drugs in horse saliva. He refused however to disclose his methods so the authorities then turned to Professor Fränkel of the University of Vienna who confirmed Bukowski's findings. Neither Bukowski nor Fränkel showed whether the presence of the drug in saliva was due to topical contamination or secretion, but the success of saliva testing may well have been due, in part at least, to the widespread practice of administering drugs orally and to the fact that only a few well defined drugs, such as caffeine, strychnine, and morphine, were available. Whatever the reason, the introduction of saliva testing brought the situation under control.

Although the introduction of horse doping into Europe is said to have come from America it was not until the 1930's that doping became a problem in the U.S.A. This was due to the introduction of on-course betting and an upsurge in the amount of racing taking place. A very high proportion of the horses taking part in races were doped and racing stables were equipped like pharmacies. Indeed, so serious was the problem that the first action to control it was taken not by the racing authorities but by the Federal Bureau of Narcotics. In a series of raids this body arrested over one hundred members of the racing fraternity. Although this resulted in a trend away from the use of narcotic drugs, it did not end the problem of doping in the United States and it was now the turn of the American authorities to seek the help of the European experts.

The Florida Racing Commission sent their chemist, Dr. Morgan, and a veterinary surgeon, Dr. Catlett, to study the methods used by Kaufman in Paris. When they returned, saliva testing was introduced into America in 1932 and again the situation came under control.

The use of narcotics gave way at the end of the Second World War to the employment of drugs like amphetamine, and other sympathomimetic compounds. This in turn gave way to the use of local anaesthetics such as procaine, and more recently to anti-inflammatory drugs such as phenylbutazone and possibly also to anti-inflammatory and anabolic steroids. Table I, which uses figures compiled by the Association of Official Racing Chemists, shows these trends more clearly.

\section{TABLE I}

Twelve most frequently reported drugs internationally between 1949 and 1974 . The number of cases involving the drug are shown as a percentage of all positive cases for the three different periods.

1949-64 1965-69 1970-74 Number (per cent) (per cent) (per cent) of times reported, 1949-1974

$\begin{array}{lrrrr}\text { Procaine } & 20 & 20 & 17 & 721 \\ \text { Caffeine } & 17 & 11 & 6 & 496 \\ \text { Amphetamine } & 15 & 10 & 6 & 471 \\ \text { Phenylbutazone } & 4 & 9 & 16 & 326 \\ \text { Methylphenidate } & 2 & 14 & 7 & 212 \\ \text { Methylamphetamine } & 2 & 5 & 3 & 135 \\ \text { Theobromine } & 3 & 5 & 2 & 131 \\ \text { Dipyrone } & 3 & 4 & 4 & 129 \\ \text { Oxyphenbutazone } & 1 & 3 & 5 & 92 \\ \text { Barbiturates } & 6 & 0 & 0 & 86 \\ \text { Pentazocine } & 0 & 2 & 3 & 69 \\ \text { Morphine } & 2 & 1 & 0 & 62\end{array}$


The control of doping has always been achieved by a combination of analytical procedures and police investigation. The first of these depends upon the identification of a drug in a body fluid of a horse. Four such fluids are available, saliva, blood, urine and sweat. Of these the first to be used, saliva, was probably chosen because of its ease of collection. The same can probably be said of sweat, though this suffers on account of the legal problems involved with possible contamination. The collection of urine samples was not introduced generally until many years later. Blood samples are not usually taken for dope-testing because of the difficulty of collection and the analytical problems they present. In addition there has always been objection from owners and trainers because of possible injury to their animals.

Despite the problems that might be expected in the collection of urine samples from horses, in Britain ninety per cent of horses produce a urine sample within one hour of racing. It has been found from results obtained over a number of years that this is by far the most suitable body fluid for dope-testing. When the urine sample has been collected it is essential that it should be sent to the laboratory as quickly as possible and under conditions of maximum security. Freshness of the sample for analysis is vital for all routine dope-testing procedures.

Although details of analytical procedures have always varied from one laboratory to another, they have usually consisted of solvent extraction, followed by various screening procedures applied to these extracts. Early workers relied almost exclusively upon the microcrystalline test. This uses the property possessed by most alkaloidal drugs, of being precipitated from aqueous solution as small crystals in the presence of certain reagents, notably salts of heavy and noble metals. The characteristic forms of these crystals are used to identify the drugs involved. It would be difficult to overstate the importance of this test in suppressing doping. In the early twentieth century toxicologists were ill-equipped for the detection of the minute quantities of drugs encountered, and the microcrystalline test, capable of detecting microgram quantities, was in its day something of a miracle.

Colour tests, although less sensitive, were also employed. Both types of test remained in use until after the end of the Second World War, and although now largely superseded do have a part to play in analytical toxicology.

During the last $\mathbf{3 0}$ years, however, there have been great changes in the methods used for the detection of drugs, due mainly to the introduction of chromatography and spectrophotometry. Paper, thin-layer, and gas chromatography have proved invaluable for screening purposes, as has ultraviolet spectrophotometry, while mass spectrometry, coupled with gas chromatography, has provided an excellent method for the final identification of an unknown drug.

The weakness of all post-race testing procedures lies in the inability to prevent the unscrupulous from profiting in the betting market by a foreknowledge of a horse having been doped. There has inevitably, therefore, been much talk of the possible introduction of pre-race testing, whereby a horse can be removed from a race if it has been found to have been doped. Such tests have in fact been applied by one or two racing authorities. The Singapore authorities have for many years used a simple test on saliva samples from runners which makes use of the property of an alkaloidal drug to form a chloroformextractable complex with certain indicator dyes. The presence of such a drug is said to be indicated by the colouration of a chloroform extract of saliva to which the indicator has been added. Such a test is, of course, very unspecific and at best could be only an indication that a doping agent might be present. Additional tests would be necessary to confirm the identity of the compound involved. The New York and Ohio authorities have used a screening procedure based upon the analysis of blood samples using gas chromatography with electron capture detectors. This scheme necessitates the use of chemical procedures which convert any drug present in the solvent extract into a special type of derivative which thereby becomes detectable in very low quantity. Unfortunately the number of drugs detectable by this method is much smaller than is the case with post-race tests, and there seems little doubt that the techniques used do require considerable operator skill. Perhaps the most serious objection is the high cost involved, particularly in racing as decentralised as in Britain, where the problem of organisation of sample collection and analytical facilities would be very great indeed. Whether such tests will prove feasible in the future must remain an open question, but there is much to recommend them if they can be applied in a practicable and economic way.

Routine dope-testing was introduced in Britain in 1963. It is interesting to correlate the occurrence of criminal doping offences with the introduction of a routine-testing programme. Between 1960 and 1965, three separate conspiracy trials took place in England involving the doping of racehorses, all resulting in convictions and heavy sentences, since when there have been no further incidents of this kind. In the first of these three cases, several attempts were made to dope horses to win by the administration of a stimulant drug. The operation was conducted by a gang which gained access to several racing stables and dosed horses with caffeine. Just how effective this operation was must be speculative, but it is interesting to note that, in a letter written by one of the conspirators to another, when the supply of caffeine had been exhausted, the remark was made 
that they didn't seem to have had much success with the stuff lately and perhaps they would do better without it! There is no doubt that the technique of doping to lose, used in the two subsequent cases, produced more predictable results. In the first of these "doping to lose" cases, favourites scheduled to run the following day, and heavily backed in the ante-post market, were found on the morning of the race to be heavily sedated and unable to participate. Phenobarbitone was found in the urine of these horses. The second series of offences occurred a few years later. This time favourites in a small field of runners were given a tranquillising drug in a dose such that, although sedated, they were able to come under starter's orders the following day, but failed to finish, or finished badly. Second favourites were heavily backed to win. A gang was subsequently arrested in the act of feeding acetylpromazine to a horse in a stable at Lambourn, in the early hours of the morning. This is the last known case of conspiracy to dope horses in Britain. Today most doping cases, though not all, involve the administration of therapeutic substances, notably antiinflammatory drugs and local anaesthetics, too close to the time of racing. 